\title{
PRÁTICAS DE ESCRITA E ARGUMENTAÇÃO EM UM EVENTO CIENTÍFICO PARA GRADUANDOS: UM ESTUDO FUNDAMENTADO NO CONCEITO BAKHTINIANO DE CONCLUSIBILIDADE DO ENUNCIADO
}

\author{
Mariana Dutra de Carvalho Lopes \\ Universidade Federal de Minas Gerais \\ Belo Horizonte, Minas Gerais, BR \\ Carlos Henrique Silva de Castro ${ }^{* *}$ \\ Universidade Federal dos Vales do Jequitinhonha e Mucuri \\ Diamantina, Minas Gerais, BR
}

\begin{abstract}
Resumo
Este trabalho investiga a participação de estudantes de graduação enquanto autores e leitores de artigos em um evento científico online a fim de verificar se eles interagem entre si por meio de enunciados plenos. A base teórica da investigação sustenta-se no conceito bakhtiniano de enunciado pleno e tem na concepção do ensino de leitura e escrita com propósitos funcionais um apoio para melhor apreensão do contexto de aprendizagem em que a pesquisa se insere. $\mathrm{O}$ evento selecionado para coleta de dados ocorre em um blog, no âmbito de uma disciplina de leitura e produção de textos, e convida os estudantes a escreverem e publicarem seus artigos, comentarem outros três trabalhos e participarem do debate no espaço de seus artigos. Para conduzir este estudo de caso, de abordagem qualitativa, foram selecionados trinta comentários de estudantes, constituintes de dois posts de artigos. O resultado da análise dos enunciados sugere que os estudantes reconheceram uma situação de interlocução e mostraram-se engajados ao participarem da atividade, exercitando as habilidades de leitura, escrita e argumentação.
\end{abstract}

Palavras-chave: Interação; Argumentação; Leitura e Escrita; Aprendizagem.

\section{PRACTICES OF WRITING AND ARGUMENTATION IN A SCIENTIFIC EVENT FOR UNDERGRADUATE STUDENTS: A STUDY BASED ON BAKHTIN'S CONCEPT OF COMPLETE UTTERANCE}

\begin{abstract}
This work investigates the participation of undergraduate students as authors and readers of articles in an online scientific event in order to verify if they interact through complete utterances. Bakhtin's concept of complete utterance and the principle of reading and writing with functional purposes were used as theoretical bases in order to support a better understanding of the learning context in which the research is inserted. The event in which the data were collected takes place on a blog, under a discipline of reading and text production, which invites students to write and publish their papers, comment on other three papers and participate in the discussion on the post of their own articles. To conduct the case of study, thirty comments from students were selected, from two posts of articles. The result of the analysis suggests that the students recognized a situation of interaction and showed their engagement while they were participating in the activity, exercising their skills of reading, writing and argumentation.
\end{abstract}

Keywords: Interaction; Argumentation; Reading and Writing; Learning.

\footnotetext{
* Possui graduação em Letras pela Universidade Federal de Minas Gerais (2004), especialização em Designer Instrucional para Ensino a Distância Virtual pela Universidade Federal de Itajubá (2010) e mestrado em Estudos de Linguagens pelo Centro Federal de Educação Tecnológica de Minas Gerais (2015). É técnicoadministrativo em educação na Universidade Federal de Minas Gerais. Tem experiência na área de Lingüística, com ênfase em Linguagem e Tecnologia e em Leitura e Produção de Textos. Seu endereço de email é maducalo@yahoo.com.br

${ }^{* *}$ Doutor em Linguística Aplicada pela Universidade Federal de Minas Gerais (2015). É mestre em Gestão Social, Educação e Desenvolvimento Local pelo Centro Universitário UNA (2010). É professor na Universidade Federal dos Vales do Jequitinhonha e Mucuri. Interessa-se pelo estudo etnográfico de comunidades online, linguagem e tecnologia, formação de professores, educação do campo, leitura e produção de textos. Seu endereço de email é chenriquebh@yahoo.com.br
} 


\section{Introdução}

Este trabalho investiga se estudantes de graduação, ao participarem de um evento científico online, interagem entre si por meio de enunciados plenos ou, em outros termos, enunciados dotados de conclusibilidade (BAKHTIN, 2006). Motiva-nos, sobretudo, a seguinte questão: ao atuarem como autores e leitores de artigos científicos em um evento online promovido no âmbito de uma disciplina, os graduandos mostram-se engajados para se comunicarem com os pares, exercitando a leitura, a escrita e a argumentação?

O evento ocorre no âmbito da disciplina Oficina de Leitura e Produção de Textos (doravante, LPT), ofertada semestralmente, na modalidade a distância, pela Faculdade de Letras da Universidade Federal de Minas Gerais. A disciplina apresenta a seguinte ementa:

Nesta oficina pretende-se desenvolver várias habilidades de escrita e de leitura de gêneros textuais importantes no âmbito acadêmico como esquema, resumo, resenha, projeto e relatório de pesquisa, bem como discutir e refletir sobre vários aspectos da língua portuguesa, relevantes para a lide com esses textos. Serão produzidos textos de vários gêneros acadêmicos na modalidade escrita, visando o aprimoramento da textualidade e de aspectos da norma culta que se fizerem necessários. (UNIVERSIDADE FEDERAL DE MINAS GERAIS, 2013)

Dessa forma, no decorrer do semestre, os estudantes trabalham, online, na plataforma Moodle, os gêneros esquema, resumo, resenha, entre outros. Ao final do semestre, individualmente ou em grupo, os estudantes produzem um artigo científico, bem como um resumo do artigo e o próprio minicurrículo. Nas semanas finais da disciplina, ofertada como eletiva a todos os estudantes da universidade, propõe-se aos participantes, como atividade avaliativa, a participação no Universidade, Educação a Distância e Software Livre - UEADSL, congresso nacional online promovido pelo Grupo Texto Livre em parceria com a Faculdade de Letras.

O evento tem duração de uma semana e ocorre em um blog, no qual cada artigo, juntamente com o resumo e o minicurrículo dos autores, é publicado em um post.
A atividade proposta aos estudantes consiste em comentar três artigos a sua escolha e mediar o debate que ocorrer sobre seu próprio artigo. Discutindo softwares livres e ensino a distância no contexto das universidades, os participantes têm a oportunidade de assumirem as posições de autores de artigos e de debatedores em mesas-redondas em ambiente digital. E o elevado número de vagas da disciplina (aproximadamente quinhentas vagas) gera um grande número de artigos escritos e de debates possíveis.

Assim, a partir da interação assíncrona possibilitada pelo campo de comentários, estudantes-autores e estudantes-leitores tornam-se produtores e destinatários de enunciados. Nesse contexto, selecionamos, do conjunto de comentários feitos pelos participantes no blog do evento, os enunciados que compõem o corpus desta pesquisa.

Considerando a questão inicialmente levantada e o ambiente selecionado para a pesquisa, estabelecemos nosso objetivo: investigar se os estudantes de uma disciplina de leitura e produção de textos, ao participarem de um evento científico online como autores e leitores de artigos, interagem entre si por meio de enunciados plenos ou, nos termos de Bakhtin (2006), enunciados dotados de conclusibilidade.

A partir dos dados selecionados no blog, analisamos a produção de enunciados pelos estudantes. Por se tratar de pesquisa qualitativa, o grau de conclusibilidade dos enunciados analisados não foi quantificado e, sim, avaliado com maior ou menor presença do atributo, de acordo com os critérios expostos na seção teórica. Essa escolha deve-se ao fato de que qualificar a conclusibilidade dos enunciados, interpretando-os a partir de categorias, permite maior compreensão da atitude dos estudantes diante de um contexto de aprendizagem que propõe uma escrita contextualizada e dialógica.

\section{Escolhas teóricas}

Bakhtin (2006), em estudo sobre os gêneros do discurso, desenvolve o conceito de "enunciado pleno" e aborda o atributo de conclusibilidade do enunciado. Um enunciado pleno é, em síntese, aquele que realiza a intenção do autor de comunicar "tudo" o que se propõe a dizer 
ao receptor da mensagem - que, no momento seguinte, o da resposta, torna-se também autor. Esse movimento pressupõe um destinatário para o enunciado, com base no qual o autor define conteúdo e forma da mensagem.

Ao utilizar o conceito bakhtiniano para analisar a interação entre estudantes em um ambiente online de uma disciplina de leitura e produção de textos, admitimos a existência de destinatários para as mensagens publicadas. Esses destinatários, para Antunes (2003), são fundamentais para que os estudantes, em um contexto de ensino da escrita, decidam o quê escrever. A autora considera, nesse sentido, que a escrita em aulas de português deve ter um "propósito funcional".

Para maior entendimento de tais questões, dividimos esta seção em duas partes. Inicialmente, tratamos do diálogo entre os autores selecionados e, na sequência, apresentamos uma síntese dos pontos de interesse para nossa análise.

\subsection{O propósito funcional da leitura e da escrita e a conclusibilidade de enunciados}

Uma aula de língua portuguesa deve privilegiar a aprendizagem em situações reais de uso da língua (ANTUNES, 2003). Assim, o estudo e a produção de textos em situações de interação com propósitos específicos, sobre temas recorrentes no cotidiano e de interesse dos estudantes, parece ser um caminho profícuo para a aprendizagem. Como explica Antunes (2003, p. 47), “[o] professor não pode, sob nenhum pretexto, insistir na prática de uma escrita escolar sem leitor, sem destinatário; sem referência, portanto, para se decidir sobre o que vai ser escrito".

No evento UEADSL, os estudantes praticam a escrita com propósitos específicos, o "propósito funcional" apontado por Antunes (2003, p. 48). No contexto do congresso, o estudante-autor escreve um artigo que será apresentado para leitura e crítica. Enquanto estudante-leitor, ele escreve críticas destinadas a autores de artigos e também às demais pessoas que acessam a página, leem e/ou comentam, numa construção conjunta de sentido para o texto em debate. Dessa forma, a participação no evento como uma atividade da disciplina LPT potencializa o desenvolvimento das habilidades de leitura e produção de textos. Antunes pontua, ainda, que, para mudarmos o quadro do ensino deslocado do português devemos "conseguir ampliar as competências comunicativo-interacionais dos alunos" (2010, p. 34). A autora se justifica da seguinte forma:

[...] a evidência de que as línguas só existem para promover a interação entre as pessoas nos leva a admitir que somente uma concepção interacionista da linguagem, eminentemente funcional e contextualizada, pode, de forma ampla e legítima, fundamentar um ensino da língua que seja, individual e socialmente, produtivo e relevante (ANTUNES, 2003, p. 41).

Notamos que os enunciados produzidos possuem aspectos interacionais específicos, como a mediação tecnológica e o debate na academia, e um estilo decorrente destes: tratam-se de réplicas e tréplicas que são, como propõe o conceito de enunciado de Bakhtin, "real unidade da comunicação discursiva” (2006, p. 274). Essas réplicas e tréplicas, ao serem analisadas como enunciados, precisam ser consideradas em sua globalidade.

No caso do nosso corpus, os textos produzidos nos comentários são enunciados elaborados por um determinado sujeito, com uma determinada intenção, em um determinado contexto, visando um determinado destinatário (conhecido ou não), abordando um determinado tema através de um determinado estilo. Bakhtin (2006) propõe como um enunciado pleno aquele que carrega em si todos esses fatores. Desconsiderando-se qualquer uma dessas peculiaridades, o enunciado torna-se apenas um conjunto de palavras ou de orações sem nexo, descontextualizado. Caso um enunciado não seja analisado como tal, mas isoladamente, fora do seu aspecto comunicativo, como apenas uma unidade da língua, não teremos uma tradução de sua completude, tal como pontua Bakhtin:

Todas essas qualidades e peculiaridades absolutamente novas pertencem não à própria oração, que se tornou enunciado pleno, mas precisamente ao enunciado, traduzindo a natureza dele e não a natureza da oração: elas se incorporam à oração completando-a até torná-la enunciado pleno. A oração enquanto unidade 
da língua carece de todas essas propriedades: não é delimitada de ambos os lados pela alternância dos sujeitos do discurso, não tem contato imediato com a realidade (com a situação extraverbal) nem relação imediata com enunciados alheios, não dispõe de plenitude semântica nem capacidade de determinar imediatamente a posição responsiva do outro falante, isto é, de suscitar resposta. A oração enquanto unidade da língua tem natureza gramatical, fronteiras gramaticais, lei gramatical e unidade (BAKHTIN, 2006, p. 278).

O conceito de enunciado é elaborado de forma esparsa por Bakhtin. Em determinados momentos, como comentado anteriormente, o autor define peculiaridades e limites dos enunciados. Em outros momentos, fazendo oposição aos enunciados, Bakhtin caracteriza também as unidades da língua, conforme ilustrado na citação anterior. A alternância entre os sujeitos do discurso, por exemplo, é fator determinante das fronteiras do enunciado (BAKHTIN, 2006, p. 279). Em um diálogo cotidiano, o enunciado de um sujeito se inicia quando o outro se silencia ou é interrompido e tem seu fim quando a enunciação do outro se inicia. Ou seja, a construção textual se dá sempre considerando o interlocutor e o contexto. Visto isoladamente, um enunciado torna-se nada mais do que uma unidade da língua. O enunciado pleno não é apenas uma sequência de palavras, é uma sequência de palavras que se relaciona de alguma forma com o contexto extraverbal e com o que já foi dito/escrito por outros falantes/autores. Essa sequência de palavras que compõe o enunciado apresenta também plenitude de sentido e é capaz de suscitar uma resposta do ouvinte/leitor.

Essas duas propriedades, plenitude de sentido, a partir da consideração do interlocutor e seu contexto, e capacidade de suscitar resposta estão intimamente relacionadas e fornecem a base para a compreensão do conceito de conclusibilidade do enunciado. A capacidade de gerar resposta surge, segundo Bakhtin (2006), da plenitude de sentido do enunciado. Assim, o enunciado pleno comunica tudo sobre a mensagem que o falante/autor deseja transmitir - sendo a abrangência desse $t u d o$, naturalmente, diferente para a réplica de um diálogo cotidiano e para uma obra científica. Esse tudo é definido pela intenção do sujeito do discurso e, ao expressar tudo, o enunciado é capaz de gerar uma compreensão responsiva por parte do ouvinte/leitor.

Um enunciado que diz tudo sobre o seu objeto de acordo com a intenção discursiva do sujeito e de uma forma coerente com essa intenção é um enunciado dotado de conclusibilidade. Explica Bakhtin:

\begin{abstract}
A conclusibilidade do enunciado é uma espécie de aspecto interno da alternância dos sujeitos do discurso; essa alternância pode ocorrer precisamente porque o falante disse (ou escreveu) tudo o que quis dizer em dado momento ou sob dadas condições. (...) Esse tudo - indício da inteireza do enunciado - não se presta a uma definição nem gramática nem abstratosemântica (BAKHTIN, 2006: 280-281).
\end{abstract}

Essa inteireza do enunciado, que assegura a possibilidade de resposta (ou de compreensão responsiva), é determinada por três elementos (ou fatores) intimamente ligados no todo orgânico do enunciado: 1) exauribilidade do objeto e do sentido; 2) projeto de discurso ou vontade de discurso do falante; 3 ) formas típicas composicionais e de gênero do acabamento (BAKHTIN, 2006, p. 280-281).

Cabe, ainda, um esclarecimento sobre a tradução da obra de Bakhtin no Brasil. Os termos utilizados neste artigo foram retirados da tradução de Paulo Bezerra do livro Estética da criação verbal - tradução feita diretamente do russo. Existe outra tradução desta obra para o português feita a partir de uma tradução francesa. Há grande divergência de termos entre essas traduções para citar um único exemplo, o conceito de conclusibilidade do enunciado, chave para o desenvolvimento desta pesquisa, foi traduzido do francês como acabamento do enunciado (BAKHTIN, 1997, p. 299). Os termos de Paulo Bezerra foram os escolhidos para este trabalho em virtude da tradução feita diretamente da língua de Bakhtin.

\subsection{O que determina a conclusibilidade do enunciado?}

O primeiro elemento que aponta a completude, a inteireza ou, ainda, a conclusibilidade do enunciado, é a exauribilidade do tema e do sentido, que é relativa. 
No caso de trabalhos científicos, por exemplo, tem seu limite definido pela própria ideia do autor, ou seja, pela profundidade e pela perspectiva com que deseja tratar o tema. Assim, a plenitude do enunciado é condizente com a intenção discursiva do autor, que corresponde ao segundo elemento de inteireza. Esta intenção "determina o todo do enunciado, o seu volume e as suas fronteiras" (BAKHTIN, 2006, p. 281).

Esse segundo elemento de inteireza do enunciado, o projeto ou a vontade de discurso do falante, a intencionalidade, determina também o terceiro, qual seja, "a escolha da forma do gênero na qual será construído o enunciado" (BAKHTIN, 2006, p. 281). E o gênero do discurso - os quais são definidos inicialmente como "tipos relativamente estáveis de enunciado" (BAKHTIN, 2006, p. 262) - será, portanto, escolhido pelo autor de acordo com sua intenção discursiva, com a projeção que faz de seus leitores e também de acordo com a situação concreta de comunicação.

Terceiro elemento de conclusibilidade, os gêneros discursivos são também discutidos por autores que consideram especificidades da produção textual em ambientes digitais. Marcuschi (2005) afirma que as novas tecnologias criam novos gêneros de discurso e que os novos meios de comunicação, por interferirem nas condições de criação de enunciados, interferem também na natureza dos gêneros produzidos. Posicionamento com o qual corroboram Levy e Stockwell (2006, p. 96), para quem "[d]iferentes tecnologias influenciam a comunicação de diferentes maneiras"1.

Retomando nosso corpus, o UEADSL, no contexto de um evento acadêmico, oferece ao estudante a oportunidade de realizar gêneros textuais que pedem registros mais formais, como o artigo científico, o minicurrículo e o resumo. Concomitantemente, por ser um blog o ambiente de interação, podem surgir marcas de informalidade nos comentários publicados. Marcuschi (2005) aponta que em um ambiente da internet como esse podem ser escritos diversos gêneros, estáveis como todo gênero (BAKHTIN, 2006), mas não estanques. Ao analisar contexto semelhante, Paiva (2007) aponta que essas produções
(...) são estruturas retóricas e linguísticas híbridas do gênero "artigo acadêmico", "ensaio", "e-mail" e "chat", pelo fato de apresentarem, respectivamente, formas discursivas mais rebuscadas (como citações de teorias, discussões metodológicas e práticas, dentre outras) e abertura e fechamento de "turnos comunicativos" comuns no gênero digital chat (PAIVA, 2007, p. 250).

Por ser um evento científico hospedado em um $b l o g$, é esperado, como apontado pela autora, o uso de formas de expressão híbridas nas intervenções. Na realização desses gêneros, o enunciado de um estudante sobre um determinado artigo se une aos demais comentários postados, o que cria uma rede de respostas e de comunicação sobre o texto e promove a interação entre os usuários - que podem ter sua opinião influenciada pela leitura de comentários alheios. Bakhtin, ao abordar o conceito de polifonia, exemplifica algumas influências de outras vozes que podem ocorrer nesse contexto de produção dialógica: "influência educativa sobre os leitores, sobre suas convicções, respostas críticas, influência sobre seguidores e continuadores" (2006, p. 279). E é contando com a presença de múltiplas vozes que os estudantes-leitores elaboram seus enunciados para comentar o artigo do estudante-autor, enunciados estes que se pressupõe serem dotados de conclusibilidade: "[c]ada réplica, por mais breve e fragmentária que seja, possui uma conclusibilidade específica ao exprimir certa posição do falante que suscita resposta, em relação à qual se pode assumir uma posição responsiva" (BAKHTIN, 2006, p. 275).

Analisar o grau de conclusibilidade desses enunciados significa, assim, verificar, no contexto da interação mediada por computador, três pontos específicos: 1) as intenções discursivas de cada comentário, 2) a exauribilidade do tema e do sentido e 3 ) as características do gênero escolhido para a sua expressão. Partimos desses três pontos para a análise dos nossos dados.

\section{Escolhas metodológicas}

Metodologicamente, quanto à finalidade, esta pesquisa enquadra-se no ramo das pesquisas aplicadas, as quais, segundo Gil (2008, p. 26-27), têm "como caracte- 
rística fundamental o interesse na aplicação, utilização e consequências práticas dos conhecimentos". Acreditamos que este estudo tenha tal caráter por investigar uma metodologia de ensino voltada para a interação, com propósito funcional, e, portanto, com possibilidade de contribuir com a reflexão sobre o ensino da língua portuguesa e com novas práticas.

Quanto aos objetivos, esta pesquisa é entendida como descritiva, a qual, segundo Gil (2008, p. 28), busca "a descrição das características de determinada população ou fenômeno ou o estabelecimento de relações entre variáveis". Assim, procuramos descrever os fenômenos observados no blog do evento, atribuindo-lhes significados, ao invés de buscar justificativas para tais ocorrências.

A partir de nossos objetivos e finalidades, entendemos o estudo de caso como o método mais adequado para a condução desta pesquisa. Segundo Yin (2001, p. 21), "o estudo de caso contribui, de forma inigualável, para a compreensão que temos dos fenômenos individuais, organizacionais, sociais e políticos." Considerando como fenômeno social o que ocorre no blog do UEADSL, buscamos, com nossas escolhas, um meio de "preservar as características holísticas e significativas dos eventos da vida real" (YIN, 2001, p. 21).

Gil (2008, p. 57-58), por sua vez, indica que "o estudo de caso é caracterizado pelo estudo profundo e exaustivo de um ou de poucos objetos, de maneira a permitir o seu conhecimento amplo e detalhado". Assim sendo, do total de enunciados produzidos pelos estudantes no $b l o g$, selecionamos uma parcela para realizarmos nossa análise a partir de observação direta.

Yin (2001, p. 115) recomenda a utilização de "protocolos de observação" para a realização da observação direta, procedimento que permite ao pesquisador "avaliar a incidência de certos tipos de comportamento". Seguindo a sugestão, desenvolvemos nossas categorias de análise a partir do conceito de conclusibilidade do enunciado (BAKHTIN, 2006) e promovemos a categorização dos dados observados. Yin (2001) também aponta a vantagem de se fotografar o local de estudo, o que ajuda a "transmitir as características importantes do caso a observadores externos" (YIN, 2001, p. 116) - fato que nos motivou a inserir neste trabalho, como citações, os enunciados analisados.
Assim, a observação estruturada constituiu nosso procedimento para coleta de dados referentes a aspectos dos enunciados produzidos pelos estudantes no blog. Nessa observação, "o pesquisador sabe quais os aspectos da comunidade ou grupo que são significativos para alcançar os objetivos pretendidos" e, por isso, "elabora previamente um plano de observação" (GIL, 2008, p. 104).

Para a observação dos enunciados, selecionamos posts específicos seguindo critérios da "amostra típica, em que, a partir das necessidades de seu estudo, o pesquisador seleciona casos julgados exemplares ou típicos da população-alvo ou de uma parte desta" (LAVILLE; DIONNE, 1999, p. 170).

Quanto à abordagem, essa pesquisa classifica-se como qualitativa. Segundo Silverman (2009, p. 51), “um ponto forte da pesquisa qualitativa é que ela usa dados que ocorrem naturalmente para encontrar as sequências ('como') em que os significados dos participantes ('o quê') são exibidos e, assim, estabelecer o caráter de algum fenômeno". Procuramos, então, discutir como os estudantes interagiram entre si no blog, considerando aspectos dos enunciados produzidos.

Como método de análise dos enunciados produzidos pelos estudantes no blog, optamos pela análise de conteúdo, a qual "consiste em desmontar a estrutura e os elementos desse conteúdo para esclarecer suas diferentes características e extrair sua significação" (LAVILLE; DIONNE, 1999, p. 214). Assim, partimos da análise de conteúdo para sugerir o grau de conclusibilidade encontrado nos enunciados.

Sobre a validade das pesquisas qualitativas, Lankshear e Knobel (2008, p. 157) afirmam que ela está relacionada à capacidade de os dados permitirem que o pesquisador encontre aquilo que procura - o que é determinado pelo método de coleta e de interpretação dos dados. Segundo os autores, "trata-se de desenvolver ferramentas de coleta de dados, através das quais realmente obtenhamos informações sobre o fenômeno", considerando a forma como o conceituamos, e de "desenvolver um relato plausível e útil", e não de estabelecer verdades absolutas. Dessa forma, considerando nosso objetivo de investigar como ocorre a participação de estudantes em uma atividade online que propõe uma 
escrita contextualizada, acreditamos que o conceito bakhtiniano de conclusibilidade do enunciado seja uma alternativa condizente com nossa intenção, capaz de permitir observações relevantes.

Com relação à confiabilidade, os autores afirmam que ela está relacionada com "o modo como desenvolvemos e implementamos nossas ferramentas de coleta de dados" (LANKSHEAR; KNOBEL, 2008, p. 158). Esse modo inclui cuidados com a equivalência de dados, isto é, com a tentativa de obter o mesmo tipo de dado de diferentes situações. Além disso, o pesquisador deve testar e checar se os dados coletados são de fato consistentes. Nesse sentido, destacamos que, no ato de categorizar os enunciados selecionados para esta pesquisa, inevitavelmente há processos subjetivos envolvidos, afinal, como propõe Hissa (2013, p. 20), "é artificial a concepção do sujeito do conhecimento que neutraliza o sujeito do mundo que deveria carregar. Não há sujeito do conhecimento do mundo e, tampouco, sujeito do saber, que não seja sujeito do mundo." De toda forma, para conferir maior confiabilidade à pesquisa, procuramos utilizar critérios equivalentes para a categorização dos enunciados e checar, em diferentes momentos, a categoria em que cada um foi classificado.

Sobre a ética em relação aos sujeitos envolvidos na pesquisa, Lankshear e Knobel (2008, p. 100) pontuam que o pesquisador deve buscar a confidencialidade e o anonimato dos participantes. Nesse sentido, removemos a autoria dos comentários coletados e, quando neles havia nomes de outros participantes, alteramo-los, nas citações, para nomes fictícios.

Esclarecemos, ainda, que o UEADSL acontece em ambiente online livre e aberto e que, em nossas pesquisas de mestrado e doutorado, obtivemos autorização da coordenadora do evento para pesquisas no $b l o g$.

\section{Apresentação e discussão dos dados}

Os artigos produzidos para o evento UEADSL podem ser escritos, conforme orientação dada na disciplina, individualmente ou em grupo e devem se vincular a um dos eixos temáticos propostos. Na edição do primeiro semestre de 2012, selecionada para essa pesquisa, foram propostos seis eixos temáticos: 1) Universidade e EaD, 2) Universidade e Software Livre, 3) EaD e Software Livre, 4) EaD e Software Livre na Universidade, 5) Cultura Livre e 6) Produção Textual no Computador (UEADSL, 2012).

Para o desenvolvimento do nosso objetivo de pesquisa - verificar o grau de conclusibilidade em enunciados produzidos por estudantes em um contexto de interação mediada que possibilita uma escrita com propósitos -, selecionamos apenas enunciados produzidos pelos estudantes matriculados na disciplina. No entanto, não podemos desconsiderar o contexto no qual esses enunciados foram produzidos, afinal, "o enunciado deve ser enfrentado na sua historicidade, na sua concretude, para deixar ver mais do que a dimensão exclusivamente linguística e/ou sua fragmentação" (BRAIT; MELO, 2010, p. 71). Dessa forma, consideramos, como contexto, os enunciados produzidos pelos professores e tutores da disciplina LPT e por participantes do evento externos à disciplina.

Para a seleção dos artigos dos quais foram retirados os enunciados componentes do corpus desta pesquisa, foram identificados, inicialmente, os três artigos listados pelo top posts do primeiro dia de evento da edição 2012.1. O ranking e os critérios de sua composição são divulgados pela própria organização do evento e incluem fatores como número de comentários publicados, número de visitas ao post e número de acessos ao artigo completo (UEADSL, 2012). No entanto, em um dos artigos, apesar da intensa participação dos leitores, não houve resposta dos autores. Como uma das intenções aqui é debater a interação e a argumentação entre estudantes, restringimos nossa análise aos outros dois artigos, em que houve resposta dos autores, por entendermos que eles apresentam mais possibilidades de observação do fenômeno.

Dos enunciados produzidos para os dois artigos, selecionamos um total de 30 comentários. Foram excluídos apenas os comentários da comissão organizadora, com as respectivas tréplicas dos autores, e um caso de comentário que fazia uma pequena correção de um erro de digitação. A escolha deu-se pelo fato de preocuparmo-nos, neste momento, com a interação entre os pares e não com os formadores. Esclarecemos que o corpus foi composto apenas pelos enunciados presen- 
tes nos comentários e não pelo próprio artigo. A seleção do corpus aconteceu após o final do evento, quando todos os enunciados já haviam sido produzidos.

Ao observar os enunciados produzidos como respostas aos artigos, percebemos formas de participação dos leitores bastante diversificadas. Alguns comentários convidavam para o diálogo, enquanto outros faziam apenas constatações. Essa diversidade também motivou distintas reações nos autores, que interagiram com seus leitores de acordo com o que estes ofereciam em seus enunciados.

Para analisarmos os elementos que compõem a completude do texto, criamos três categorias, que correspondem a enunciados de baixa, média e alta conclusibilidade. Citamos aqui alguns exemplos de comentários publicados por estudantes para ilustrar essas categorias. Nas seções seguintes aprofundamos o debate sobre cada uma delas, incluindo os demais comentários selecionados para este estudo.

Os enunciados de baixa conclusibilidade apresentam pontos de vista sem argumentação ou discordam sem justificativas ou elogiam sem explicitar o quê, como no exemplo a seguir: "A educação à distância e o uso de softwares livres são realmente potenciais recursos de disseminação de conhecimento. Contudo, ainda demandam qualidade técnica e de conteúdo."

Os enunciados de média conclusibilidade, por sua vez, comentam com argumentação que explicita a intenção, mas sem fazer novas proposições ou sem reconhecer o interlocutor, como pode ser percebido no comentário que se segue: "Muito interessante o texto. A abordagem sobre a EAD é bem pertinente e esclarecedora. Parabéns, conseguiram fundamentar bem o texto, facilitando seu entendimento!"

Os enunciados construídos a partir de algum ponto específico do artigo, de forma coerente com a intencionalidade observada e apresentando novos argumentos, são entendidos como de alta conclusibilidade: "Gostei muito do artigo, a abordagem está clara e objetiva. É evidente a importância da informática na educação, infelizmente no nosso país vem acontecendo lentamente, muitas barreiras, principalmente culturais devem ser quebradas."

Nas seções que seguem, 4.1 e 4.2, apresentamos nossas análises, fundamentadas nas teorias que nos amparam e nas categorias estabelecidas. Para tanto, consideramos, além das intenções e do gênero discursivo, o contexto em que as interações ocorreram, o que inclui fatores como a participação no evento ser uma atividade avaliativa de uma disciplina de graduação e o conjunto de comentários de cada post.

\subsection{Comentários publicados sobre o primeiro artigo}

Em análise preliminar do primeiro artigo selecionado, apresentado por um grupo de seis autores, notamos que uma das autoras respondeu a todas as réplicas que foram elaboradas a partir da leitura de seu artigo. Tal fato aponta para uma construção textual coerente com a intencionalidade dos estudantes-leitores e da estudante-autora, que vem, na maioria das vezes, exaurir o tema em questão a partir dos questionamentos e posicionamentos expressos pelos colegas.

O contexto interativo de réplicas e tréplicas, assíncronas, mas de rápido retorno, traz para a discussão de âmbito acadêmico marcas textuais próprias da linguagem oral, tal como se percebe em seções de chat, em $e$-mails, postagens em redes sociais, entre outros (PAIVA, 2007; MARCUSCHI, 2005; LEVY, STOCKWELL, 2006). No caso do primeiro artigo, a frequência de marcas da oralidade é pequena. Encontramos, no Comentário $\mathrm{L}$, a expressão "queridos autores" como vocativo $\mathrm{e}$, no Comentário N, a interjeição "nossa”. De maneira geral, o estilo dos 18 comentários observados aproximase do texto acadêmico, com argumentação que busca comprovar as teses postas e criar uma teia discursiva em torno do tema em análise. Notamos que se trata, em geral, de enunciados com elevada completude, como buscamos ilustrar nas análises dos comentários desse post, ponto de partida para a interação.

O contexto da interação, como já explicitado, é o ambiente acadêmico, com a diferença que o fato de estar online e aberto parece proporcionar: a funcionalidade da escrita. Neste ambiente, os temas em debate geram uma teia discursiva difícil de ser notada na escrita sem propósito, aquela em que o estudante escreve apenas para o professor e, portanto, com limitado estímulo. Ainda que a participação no evento consista em 
uma etapa da avaliação da disciplina que o promove, o que implica certa obrigatoriedade nessa participação, notamos, na maioria dos comentários analisados, interação direta entre autores e leitores por meio de réplicas e tréplicas, como buscamos explicitar a partir de agora.

No Comentário A, a seguir, a estudante-leitora, apesar de não se dirigir explicitamente aos estudantes -autores, dialoga diretamente com o artigo, como podemos observar:

\section{Comentário A: \\ Gostei muito do artigo, a abordagem está clara e objetiva. \\ É evidente a importância da informática na educação, infelizmente no nosso país vem acontecendo lentamente, muitas barreiras, principalmente culturais devem ser quebradas.}

\section{Comentário B:}

Obrigada, Fabiana ${ }^{2}$ !

É clara (sic) as críticas preconceituosas que a educação a distância sofre no Brasil. Porém, essas críticas são feitas, geralmente, por pessoas sem informação sobre essa modalidade de educação ou por instituições que ministram aulas presenciais. No entanto, essas críticas começam a perder forças diante das inúmeras possibilidades e vantagens que a EAD vem demonstrando no Brasil e uma das vantagens que ela oferece é o processo de ensino-aprendizagem que busca dar ao aluno a oportunidade de um aprendizado independente, auxiliado por tecnologias como a internet. $\mathrm{Na} \mathrm{EAD}$, o próprio aluno pode organizar seus horários e sua rotina de estudos, de acordo com sua disponibilidade. Segundo o MEC, a EAD vem crescendo muito rápido no Brasil, mas ainda há muitas melhorias a serem feitas.

Entendemos o Comentário A como um enunciado de alta conclusibilidade, pois é coerente com a intencionalidade notada no texto, a de elogiar, acrescentando, ainda, novos argumentos para fundamentar a opinião. A tréplica da estudante-autora, expressa no Comentário B, também a entendemos como de alta conclusibilidade, pois considera a mensagem do destinatário e responde a questão levantada - barreiras culturais no uso de informática na educação. Para finalizar, a estudante-autora ainda acrescenta novos dados que poderiam fomentar maior discussão.
As réplicas a seguir, todas de leitores, comentam o texto apontando questões como abordagem do tema, referencial teórico e estrutura do artigo. No entanto, essas réplicas não discutem ideias, não apresentam novos argumentos, limitando-se a aspectos identificados no artigo. Dessa forma, foram considerados de média conclusibilidade.

\section{Comentário C:}

Muito interessante o texto. A abordagem sobre a EAD é bem pertinente e esclarecedora. Parabéns, conseguiram fundamentar bem o texto, facilitando seu entendimento!

\section{Comentário D:}

Abordagem muito boa sobre a necessidade dos softwares livres para a evolução da modalidade de ensino a distância. $\mathrm{O}$ artigo está muito bem fundamentado e objetivo.

\section{Comentário E:}

Gostei bastante do artigo! A discussão sobre o emprego de softwares livres na educação a distância ficou muito bem fundamentada e a estrutura do artigo está muito boa, conforme as normas da ABNT! O grupo mostrou total interesse e dedicação na construção do artigo. Parabéns!

\section{Comentário F: \\ Prezados autores, Muito bom o seu artigo. As questões levantadas são pertinentes e bem fundamentas. $\mathrm{O}$ artigo possui um bom referencial teórico e foi utiliza- do de forma correta. Parabéns!}

No Comentário C, como podemos observar, a estudante-leitora fala da abordagem e da pertinência do tema escolhido. O Comentário D, por sua vez, elogia o tratamento dado à necessidade dos softwares livres na educação e ao estilo objetivo do texto. O Comentário $\mathrm{E}$ aborda o gênero - fundamentação e estrutura do artigo - e o estilo - uso de normas ABNT - para embasar seus elogios. O Comentário F, por fim, usa também elementos estruturais do gênero artigo para justificar os elogios ao texto. Por apresentarem uma construção adequada à intencionalidade dos autores, a de comentar e elogiar o artigo, mas não apresentarem argumentos para provo- 
car a continuidade do diálogo, esses quatro comentários foram considerados de média conclusibilidade.

Tendo em vista que as réplicas analisadas no parágrafo anterior não apresentam novos argumentos para o debate, temos como resultado apenas respostas de agradecimento da estudante-autora, que também atende à intencionalidade do seu enunciado, qual seja, a de agradecer o elogio. Como as mensagens continham apenas a expressão "agradeço o comentário", as respostas aos Comentários C, E e F foram suprimidas dessa exemplificação e, como se mostram coerentes com a intenção da autora, foram consideradas de média conclusibilidade.

Apenas em resposta ao Comentário D, a autora acrescentou novas ideias ao debate, como a questão dos ganhos em termos de custos que o uso de softwares livres representa para a EAD e a universidade. A estudante-autora mostra-se, como notamos, sempre disposta ao diálogo e coerente em suas intenções discursivas. Assim, consideramos o Comentário G de alta conclusibilidade.

\section{Comentário G: \\ Obrigada, Laura. \\ A inserção dos softwares livres na EAD faci- lita a administração dos AVAs de acordo com as necessidades de cada curso, com custos de infraestrutura mais baratos e, possibilita a in- clusão digital dentro das universidades.}

O Comentário $\mathrm{H}$, a seguir, diferentemente das réplicas que ilustramos anteriormente, o entendemos como de baixa conclusibilidade. O enunciado faz assertivas a partir do tema do texto, sem demonstrar dialogar com os autores ou com o artigo. De toda forma, a estudante-leitora provoca uma tréplica da estudante -autora que apresenta novos argumentos, desenvolve as ideias e, igualmente, não dialoga. Assim, consideramos o Comentário I como de média conclusibilidade.

\section{Comentário H:}

A educação à distância e o uso de softwares livres são realmente potenciais recursos de disseminação de conhecimento. Contudo, ainda demandam qualidade técnica e de conteúdo.

\begin{abstract}
Comentário I:
Na educação a distância é preciso avaliar o ambiente virtual de aprendizagem (AVA), os materiais ali fornecidos e a interação que ocorre nesse ambiente que envolve tecnologia, como a utilização dos softwares livres, que demandam custos de infraestrutura mais baratos e possibilitam uma melhor administração do AVA, de acordo com as necessidades de cada curso, porém a EAD e o emprego dos softwares livres nessa modalidade de ensino ainda precisam ser melhor desenvolvidos e aprimorados.
\end{abstract}

No Comentário J, a estudante-leitora comenta o estilo do texto - claro e sucinto - e, ainda, argumenta acrescentando a questão dos tabus que envolvem a EAD. A provocação deixada gera interação e encontra na tréplica um reconhecimento da inteireza do comentário. $\mathrm{O}$ Comentário $\mathrm{K}$ constrói a argumentação trazendo a questão dos tabus relativos à qualidade dos cursos a distância e dos benefícios do uso dos softwares livres na educação para a disseminação da informação. Assim, por dialogarem entre si, trazendo novos argumentos para explorarem o objeto em discussão, foram considerados de alta conclusibilidade.

\section{Comentário J: \\ Caros autores, o artigo ficou preciso e discorre de forma clara e sucinta o tema EAD e software livre possibili- tando que qualquer pessoa que leia o artigo te- nha uma visão sobre o assunto. A utilização da informática na educação é um grande avanço nessa área, pois permite que os usuários dessas modalidades tenham uma grade flexional na realização das atividades. Entretanto, há vários tabus a serem quebrados sobre o funcionamen- to da EAD no Brasil.}

\section{Comentário K:}

Muito obrigada, Gisele!

De fato ainda há muitos tabus a respeito da qualidade da educação a distância que precisam ser quebrados. Porém, sabe-se que a EAD vem crescendo muito no país e os benefícios que a inserção da informática traz para a educação como, por exemplo, o emprego de softwares livres na EAD, contribuem para a distribuição de informações e facilita a comunicação entre os usuários. 
O mesmo ocorre na sequência de comentários a seguir. No Comentário L, a estudante-leitora dialoga com o texto e com os estudantes-autores demandando uma informação, uma dica de revista com a temática softwares na universidade. Na tréplica, Comentário $\mathrm{M}$, a estudante-autora responde à questão posta e agradece o elogio recebido. Notamos, ainda, que a estudante-autora traz uma referência externa ao diálogo para a discussão, a indicação do periódico. Assim, foram ambos considerados de alta conclusibilidade.

\section{Comentário L: \\ Queridos autores, além da Revista Eletrônica de Ciência Administrativa, vocês conhecem outras que publiquem a favor da utilização de softwares nas universidades? \\ Parabenizo o artigo muito bem escrito de vocês.}

\section{Comentário M: \\ Prezada Maria, \\ Foi meio difícil encontrarmos Revistas Eletrô- nicas que tivessem artigos que tratassem sobre softwares livres nas universidades, mas há a Revista Brasileira de Aprendizagem Aberta e a Distância. Muito obrigada pelo elogio sobre o nosso artigo!}

Por último, temos o Comentário $\mathrm{N}$, que reconhece a importância do artigo apresentado, ao afirmar que o utilizaria como referência bibliográfica. Por realizar sua intenção discursiva, a de elogiar, ressaltando possíveis aplicações do artigo, o Comentário $\mathrm{N}$ foi entendido como de alta conclusibilidade. O elogio encontra na tréplica, Comentário $\mathrm{O}$, um enunciado que atende às intenções da autora de agradecer o elogio. Os pontos de exclamação revelam a motivação da estudante, mas, como o comentário não apresenta novas proposições, foi entendido como de média conclusibilidade.

\section{Comentário N:}

Muito bom o artigo. Nossa se tivesse sido publicado antes de um trabalho que fiz com relação a isso, eu teria incluído nas minhas referências. Gostei mesmo da abordagem!

\section{Comentário O:}

Obrigada, Pedro!
Fico feliz que tenhamos contribuído com algo! Um abraço.

Como pudemos observar, a maioria dos participantes se engajou no diálogo, produzindo enunciados com intenções discursivas claras, explorando o objeto temático e reconhecendo a existência de interlocutores. A estudante-autora, por sua vez, como representante do grupo autor do artigo, também mostrou-se motivada com a atividade e respondeu aos seus leitores com comentários de média a alta conclusibilidade. O Comentário $\mathrm{H}$ mostra-se como único exemplo de baixa conclusibilidade em todos os enunciados selecionados. Isso significa que, do total de enunciados, um percentual inexpressivo aparentemente não reconhece a existência de interlocutores.

\subsection{Comentários publicados sobre o segundo artigo}

O segundo artigo analisado, diferentemente do primeiro, foi escrito por um único estudante. Ele respondeu à maioria dos comentários publicados e sua participação também criou tréplicas que dialogam com os enunciados anteriores. $\mathrm{O}$ gênero textual notado tem mais marcas de informalidade do que as encontradas no primeiro artigo. Nos comentários analisados, a seguir, aparece, por exemplo, uma construção de tréplicas que se iniciam com expressões afirmativas, que têm o intuito de concordar com as ideias expostas nas réplicas e conduzir o diálogo - o que também nos remete às estruturas de réplicas e tréplicas de sessões de chat.

No Comentário $\mathrm{A}$, a estudante-leitora não define seu interlocutor, mas, em tom elogioso, fala do tema e recupera elementos do artigo em discussão com expressões como "ferramentas assim". Finaliza sua argumentação com uma afirmação que, em princípio, parece não suscitar resposta. Contudo, o que se nota é uma tréplica do estudante-autor no Comentário 2, que também remete ao artigo e reforça a argumentação. Dessa forma, entendemos o Comentário A como de média conclusibilidade e o Comentário B como de alta, tendo em vista que atende à intencionalidade de responder à questão posta na réplica e continuar o diálogo. 


\section{Comentário A:}

O tema do artigo é bastante contemporâneo, são ferramentas assim que nos auxiliam e tornam a internet cada vez mais interessante e importante.

\section{Comentário B:}

Sim, com a internet fazendo cada vez mais parte do dia a dia das pessoas, todos os setores devem se adequar a isso, e não seria diferente para o setor de pesquisa.

$\mathrm{Na}$ segunda sequência, temos uma réplica de alta conclusibilidade que suscita uma tréplica de alta conclusibilidade. No Comentário C, o estudante-leitor incia sua explanação elogiando o trabalho do autor. Justifica o elogio com a informação de que trabalha na área abordada no texto (mídia) e, ao registrar "como você mencionou", nos permite inferir que está tecendo um diálogo com o autor do artigo. Finaliza o texto com uma provocação: sugere mais pesquisa e mais dados, o que suscita uma resposta do estudante-autor.

\section{Comentário C:}

Boa tarde, Lucas, inicialmente gostaria de parabenizá-lo pelo texto, gostei muito do tema (até porque trabalho com mídia, no que diz respeito a relações de poder, construção de imagens etc.). Dessa forma, como você mencionou, as redes sociais possibilitam a visualização do perfil dos consumidores, assim como pode conquistar novos consumidores, pois seu alcance é enorme. Creio que você pode desenvolver mais ainda essa pesquisa, nos trazendo mais dados. Parabéns!

\section{Comentário D: \\ Obrigado. \\ Com certeza, essa pesquisa pode e deve ser aprofundada, alguns institutos de pesquisa já estão em busca de aprimoração a partir desse meio, e como trabalho neste ramo, estou sem- pre pensando nessas novas possibilidades de coleta de informações.}

No Comentário D, o autor afirma "com certeza" e justifica seu interesse na proposta pelo fato de trabalhar na área de pesquisa em debate no artigo. O estudante-autor acrescenta ainda que tem pensado em novas possibilidades de coleta de informações. Assim, o Comentário
D atende à intenção de responder a questão levantada, inserindo novos argumentos, o que nos leva a classificá -lo como um enunciado de alta conclusibilidade.

No Comentário E, também entendido como de alta conclusibilidade, a estudante-leitora recupera a questão do treinamento para pesquisadores, citada no artigo, e argumenta sobre as necessidades de sua adaptação às novas tecnologias. O estudante-autor, por sua vez, no Comentário F, inicia seu turno de fala com a afirmativa "sim", sinalizando um diálogo, e argumenta, acrescentando que a necessidade de novos treinamentos para os pesquisadores ocorre pelo impacto das novas tecnologias na coleta de dados. Trata-se de uma tréplica de alta conclusibilidade.

\section{Comentário E: \\ Olá, Lucas. \\ É uma grande novidade essa mudança no setor de pesquisa de opinião pública. \\ Como é dito em seu artigo, antes era neces- sário treinar os pesquisadores para chegar ao público alvo, dentre outros objetivos. E hoje, com o acesso às redes sociais, seria interessante pensarmos no novo treinamento exigido desse emergente pesquisador.}

\section{Comentário F:}

Sim, em redes sociais a forma de coleta de dados será diferente, e isso deverá ser bem trabalhado para que se obtenha dados mais confiáveis.

O Comentário $\mathrm{G}$ ponderou os elogios ao artigo, trazendo à discussão uma polêmica em relação à temática: o uso de dados pessoais de usuários de redes sociais. A intenção do estudante-autor parece ser a de expandir a discussão de modo a alcançar outros aspectos não observados no artigo. O estudante-autor, então, no Comentário $\mathrm{H}$, dá continuidade ao diálogo, ponderando que as redes disponibilizam recursos para que os usuários definam quais dados compartilhar. Nessa sequência de comentários, portanto, ambos foram entendidos como de alta conclusibilidade.

\section{Comentário G:}

Prezado autor,

Considero muito polêmico o assunto abordado. Apesar de concordar com o potencial de 
divulgação das redes sociais, minha tendência sempre será olhar todos os pontos negativos, como exposição excessiva da vida pessoal devido ao uso inadequado da ferramenta. Portanto, o bom relacionamento com o "mundo virtual" é fruto da leitura do "manual de instruções", com auxílio desse, nunca haverá erros.

\section{Comentário $\mathrm{H}$ :}

A questão de privacidade realmente é um assunto muito polêmico, mas em redes sociais é disponibilizado (sic) recursos para que você escolha para quem as informações sejam compartilhadas. As pesquisas chegariam apenas a pessoas que dariam esse acesso aos seus interesses, ou quiserem que suas opiniões sobre certos assuntos sejam lidos por qualquer pessoa.

Para finalizar, apresentamos quatro comentários. Apesar de, cada um a sua maneira, convidar o estudante-autor para o debate, esses comentários não obtiveram tréplicas. Nesse ponto cabe uma observação sobre a cronologia das postagens. Os quatro comentários iniciais foram respondidos em uma única visita do estudante-autor ao blog, no quarto dia do evento. Os quatro últimos comentários, apresentados a seguir, foram publicados após esse momento. Se, por um lado, esse dado contextual retira dos enunciados a responsabilidade de não ter suscitado resposta, por outro lado, esse mesmo dado questiona a motivação do estudante-autor com sua participação no evento.

\section{Comentário I:}

Os hábitos e interesses de consumidores tornaram-se mais acessíveis e 'reais' através das redes sociais, já que o monitoramento dos usuários provê riquíssima base de dados. E está aí o sucesso do Facebook, que ao monitorar 'likes' e compartilhamentos é capaz de traçar perfis de compra e comercializá-lo aos interessados.

\section{Comentário J:}

Gostei do tema proposto, Lucas. As redes sociais facilitam o acesso das empresas aos usuários. Se antes era preciso ir às ruas para fazer pesquisa de mercado, hoje, com alguns clicks, as empresas são capazes de mapear seus diversos(ou potenciais) consumidores.
O Comentário I não determina um interlocutor, mas busca acrescentar um ponto de vista sobre o assunto, especificamente sobre o monitoramento de perfis de consumidores do Facebook. Trata-se de uma questão nova e polêmica, mas que não suscitou resposta. O Comentário J, por sua vez, tem como interlocutor o estudante-autor, a quem direciona um elogio pelo tema escolhido. Indiretamente, este comentário dialoga com o anterior na medida em que compartilham a mesma opinião referente ao monitoramento de usuários do $\mathrm{Fa}$ cebook. Assim, entendemos ambos como enunciados de alta conclusibilidade, uma vez que trazem novos argumentos, justificam seus posicionamentos e apresentam potencial para gerar resposta.

O caso dos Comentários Ke L é semelhante. Ambos dialogam com o tema em debate, sem um interlocutor definido, mas acrescentando novos argumentos a favor ou contra o posicionamento adotado no artigo. Tratamse, assim, de enunciados de alta conclusibilidade.

\begin{abstract}
Comentário K:
Por mais óbvio que possa ser, atualmente a palavra de ordem é globalização. Barreiras geográficas praticamente não existem quando se quer conhecer sobre algo ou sobre pessoas. $\mathrm{O}$ marketing foi uma das áreas mais favorecidas com o advento e desenvolvimento das redes sociais uma vez que pessoas com os mais diversos perfis podem se encontrar e formar grupos com seus semelhantes.
\end{abstract}

\section{Comentário L:}

Eu acho que, no Brasil, as redes sociais ainda são fontes poucos confiáveis de pesquisa. Podemos ter idéias de comportamentos, alguns gostos, mas algo mais a fundo é preciso (sic) creio que estamos um pouco distantes.

$\mathrm{Na}$ análise deste segundo post, observamos um alto número de enunciados com alta conclusibilidade, o que revela, possivelmente, uma motivação efetiva dos estudantes para participarem do evento. No entanto, qual é o limite dessa motivação? Por que os últimos quatro comentários não obtiveram resposta? O que determina a forma de participação dos estudantes? Qual é o papel dos estímulos externos? 


\section{Considerações finais}

O trabalho buscou investigar se os estudantes de uma disciplina de leitura e produção de textos, ao participarem, no âmbito de uma atividade avaliativa, de um evento científico online e aberto como autores e leitores de artigos, interagiam entre si por meio de enunciados plenos ou, nos termos de Bakhtin (2006), enunciados dotados de conclusibilidade. Obtivemos, durante a pesquisa, exemplos claros de que os enunciados produzidos, em geral, dialogam de alguma forma com os autores ou com o artigo e, assim, seus autores colaboram entre si para a construção do conhecimento.

A partir dos estudos dessa pequena parte de dados do congresso UEADSL, notamos que o formato e a proposta do evento contribuem para a construção de enunciados plenos. Contribui para tanto a metodologia de ensino utilizada, que prioriza o abandono de uma prática de escrita superficial, sem um interlocutor real, tão desmotivante quanto ineficaz, e cria uma situação oportuna para o estudante compreender as múltiplas funções sociais da linguagem.

Ilustra-se, assim, o pressuposto de Antunes (2003), de que uma aula de língua portuguesa, para melhores resultados, deve apresentar um propósito funcional para a leitura e a escrita. A afirmação leva em conta, além dos resultados obtidos, a discussão pública dos trabalhos desenvolvidos ao longo do semestre, que reflete, também, o conhecimento dos estudantes sobre temas relevantes na sua formação, como universidade, educação a distância, softwares livres e outros correlatos.

Ao início deste trabalho, propusemo-nos uma questão: ao atuarem como participantes de um congresso, há engajamento dos estudantes para se comunicarem com os pares, exercitando as habilidades de leitura, escrita e argumentação? Pelos comentários aqui analisados e pela discussão alcançada, a resposta não pode ser negativa. Os exemplos nos mostram o quanto o espaço alternativo ao ambiente, digital ou não, em que acontecem as aulas pode estimular a prática das habilidades citadas. Sobretudo se considerarmos que no espaço aberto há uma audiência externa à sala de aula, que participa e contribui com suas leituras e comentários. Se, por um lado, esse fator pode inibir a participação, os dados nos mostram que o congresso torna possível o propósito funcional que o ensino de línguas pede.

Não pretendíamos aqui esgotar a reflexão sobre o uso de atividades interativas com propósito funcional no ensino de leitura e produção de texto, mas cremos ter contribuído para a pesquisa neste campo e para o diálogo sobre o tema.

\section{Notas}

1. Tradução livre.

2. Todos os nomes citados nos comentários foram substituídos por nomes fictícios.

\section{Referências}

ANTUNES, Irandé. Aula de Português: encontro \& interação. São Paulo: Parábola, 2003.

BAKHTIN, Mikhail. Os gêneros do discurso. In.: Estética da criação verbal. São Paulo: Martins Fontes, 1997.

Os gêneros do discurso. In.: Estética da criação verbal. São Paulo: Martins Fontes, 2006.

BRAIT, Beth; MELO, Rosineide de. Enunciado/enunciado concreto/enunciação. In.: BRAIT, Beth. Bakhtin: conceitos-chave. São Paulo: Contexto, 2010, p. 61-78.

GIL, Antônio Carlos. Métodos e técnicas de pesquisa social. 6a ed. São Paulo: Editora Atlas, 2008.

HISSA, Cássio Eduardo Viana. Entrenotas: compreensões de pesquisa. Belo Horizonte: Editora UFMG, 2013.

LANKSHEAR, Colin; KNOBEL, Michele. Panorama da coleta de dados na pesquisa qualitativa. In: Pesquisa pedagógica: do projeto à implementação. Porto Alegre: Artmed, 2008, p.149-166.

LAVILLE, Christian; DIONNE, Jean. A construção do saber: manual de metodologia da pesquisa em ciências humanas. Porto Alegre: Editora Artes Médicas Sul Ltda.; Belo Horizonte: Editora UFMG, 1999.

LEVY, Mike; STOCKWELL, Glenn. Computer-Mediated Communication. In.: CALL Dimensions: options and issues in computer-assisted language learning. Mahwah, New Jersey: L. Erbaum Associates, 2006, p.84-109.

MARCUSCHI, Luiz Antônio. Gêneros textuais emergentes no contexto da tecnologia digital. In.: MARCUSCHI, L. A.; XAVIER, A. C.. Hipertexto e gêneros digitais. Rio de Janeiro: Lucerna, 2005.

PAIVA, Vera Lúcia Menezes. Reflexões sobre ética e pesquisa. Rev. Brasileira de Lingüística Aplicada, 44 v. 5, n. 1, p. 43-61, 2005. 
PAIVA, Vera Lúcia Menezes; RODRIGUES-JÚNIOR, Adail Sebastião. "O footing do moderador em fóruns educacionais". In.: ARAÚJO, Júlio César (org.). Internet e ensino: novos gêneros, outros desafios. Rio de Janeiro: Lucerna, 2007, p.144-164.

SILVERMAN, David. O que é pesquisa qualitativa? In: Interpretação de dados qualitativos: métodos para análise de entrevistas, textos e interações. Porto Alegre: Artmed, 2009, p.42-66.

UNIVERSIDADE, EDUCAÇÃO A DISTÂNCIA E SOFTWARE LIVRE. Top posts. 2012. Disponível em: $<$ http://www.textolivre.pro.br/blog/?page_id=2554>. Acesso em: 05/06/2013.

UNIVERSIDADE, EDUCAÇÃO A DISTÂNCIA E SOFTWARE LIVRE. 2012. Disponível: em: <http:// ueadsl.textolivre.pro.br/2012.1/papers/pub/>. Acesso em: 05/06/2013.

UNIVERSIDADE FEDERAL DE MINAS GERAIS. Faculdade de Letras. 2013. Disponível em < http:// grad.letras.ufmg.br/o-curso-de-letras/projetopedagogico-arquivos-parciais/4-a-Ementas.pdf $>$. Acesso em 08/11/2013.

YIN, Robert K. Estudo de caso: planejamento e métodos. 2. ed. Porto Alegre: Bookman, 2001.

Recebido em: 29/02/2016 Aceito em: 11/07/2016 